\title{
Hexanal Vapor Is a Natural, Metabolizable Fungicide: Inhibition of Fungal Activity and Enhancement of Aroma Biosynthesis in Apple Slices
}

\author{
Jun Song ${ }^{1}$, Rujida Leepipattanawit ${ }^{2}$, Weimin Deng ${ }^{2}$, and Randolph M. Beaudry ${ }^{3}$ \\ Horticulture Department, Michigan State University, East Lansing, MI 48824
}

\begin{abstract}
Additional index words. Penicillium expansum, Botrytis cinerea, hexanol, hexylacetate, volatiles, antifungal, permeability, SPME, fast chromatographic detector, modified-atmosphere packaging, flavor, minimally processed
\end{abstract}

\begin{abstract}
Hexanal vapor inhibited hyphae growth of Penicillium expansum and Botrytis cinerea on potato dextrose agar (PDA) and on apple (Malus domestica Borkh.) slices. After 48 hours exposure to $4.1 \mu \mathrm{mol} \cdot \mathrm{L}^{-1}(100 \mathrm{ppm})$ hexanal, the hyphae growth of both fungi was about $50 \%$ that of untreated controls. At a concentration of $10.3 \mu \mathrm{mol} \cdot \mathrm{L}^{-1}(250 \mathrm{ppm})$, neither fungus grew during the treatment period, however, some growth of both fungi occurred 120 hours after treatment. At concentrations of hexanal vapor of $18.6 \mu \mathrm{mol} \cdot \mathrm{L}^{-1}(450 \mathrm{ppm})$ or more, the growth of both fungi ceased and the organisms were apparently killed, neither showing regrowth when moved to air. When fungi were allowed to germinate and grow for 48 hours in hexanal-free air, a subsequent 48 -hour exposure to $10.3 \mu \mathrm{mol} \cdot \mathrm{L}^{-1}$ hexanal slowed colony growth relative to controls for several days and a 48-hour exposure to $18.6 \mu \mathrm{mol} \cdot \mathrm{L}^{-1}$ stopped growth completely. Concentrations of hexanal that inhibited fungal growth on PDA also retarded decay lesion development on 'Golden Delicious' and on 'Jonagold' apple slices. Hexanal was actively converted to aroma volatiles in 'Jonagold' and 'Golden Delicious' apple slices, with hexanol and hexylacetate production strongly enhanced after 20 to 30 hours treatment. A small amount of butylhexanoate and hexylhexanoate production was also noted. Within 16 hours after treatment, no hexanal could be detected emanating from treated fruit. Since hexanal was metabolized to aroma-related volatiles by the fruit slices, the possibility of hexanal being an essentially residue-less antifungal agent seems likely. The possibility of developing a system for treating apple slices with hexanal in modified-atmosphere packages was also examined. The permeability of low-density polyethylene (LDPE) film to hexanal and hexylacetate was, respectively, about 500- and 1000-fold higher than LDPE permeability to $\mathrm{O}_{2}$. The permeability of both compounds increased exponentially with temperature, with hexanal permeability increased 6-fold while hexylacetate increased only 2.5 -fold between 0 and $30{ }^{\circ} \mathrm{C}$.
\end{abstract}

Loss of perishable fruit and vegetables during the postharvest period is estimated to range from $20 \%$ to $25 \%$ despite the use of sophisticated postharvest storage facilities and techniques (Jeffries and Jeger, 1990; Kelman, 1989). Of these losses, decay accounts for a significant proportion. Many kinds of synthetic fungicides have been used to prevent the decay of perishable plant products, although, some may pose carcinogenic risks, which has led to public concern (Wisniewski and Wilson, 1992). As a result, fungicides will face greater restrictions and limitations in the future. Using natural products with fungistatic properties may be an attractive alternative to prevent decay. Wilson et al. (1991) noted that a number of natural volatile compounds have fumigative effects. Six-carbon $\left(\mathrm{C}_{6}\right)$ aldehydes have been found to inhibit the hyphae growth of Alternaria alternata and Botrytis cinerea (Hamilton-Kemp et al., 1992). Six-carbon aldehydes, with or without double bounds, are dominant compounds released by plant material through the lipoxygenase pathway after tissue damage (Vick and Zimmerman, 1987). It has not been determined if these wound volatiles are involved in the active or passive defense systems in the plant.

Six-carbon aldehydes are also important precursors for the formation of $\mathrm{C}_{6}$ alcohols and $\mathrm{C}_{6}$ esters, which are among the most abundant volatile compounds in apple, pears, and bananas and

Received for publication 19 Dec. 1995. Accepted for publication 6 June 1996 Research conducted at Horticulture Dept., Michigan State Univ. Mention of a trademark and proprietary product does not imply endorsement of the products named nor criticism of similar ones not named. The cost of publishing this paper was defrayed in part by the payment of page charges. Under postal regulations, this paper therefore must be hereby marked advertisement solely to indicate this fact. ${ }^{1}$ Research associate.

${ }^{2}$ Graduate student.

${ }^{3}$ Associate professor. contribute to typical fruity odors (Paillard, 1986, 1990). Headspace treatment with $\mathrm{C}_{6}$ aldehydes can enhance total aroma production in 'Golden Delicious' apple fruit in low $\mathrm{O}_{2}$ storage (De Pooter et al., 1983). Even immature fruit, for which volatile biosynthesis is extremely low, respond to $\mathrm{C}_{6}$ aldehyde application with enhanced aroma volatile biosynthesis (Song and Bangerth, 1994).

In this study, our objective was to explore the potential of using hexanal vapor as a natural, metabolizable fungicide for minimally processed (sliced) apple. We wished to determine the effect of hexanal vapor on hyphae growth of Penicillium expansum and $B$. cinerea on artificial medium and on apple fruit slices. In addition, we intended to determine the extent to which aroma volatile production of apple slices was enhanced by the interconversion of hexanal vapor to aroma volatiles and whether hexanal itself emanated from treated fruit at detectable levels. Finally, we sought to measure the permeability of low-density polyethylene (LDPE) film to hexanal and hexylacetate over a temperature range of 0 to $30^{\circ} \mathrm{C}$ to determine the feasibility of using hexanal in packaged apple slices.

\section{Materials and Methods}

Biological technique. Pure strains of the fruit pathogens $P$. expansum and $B$. cinerea were obtained, respectively, from the American Type Culture Collection (Rockville, Md.) and the laboratory of Rodney Roberts (USDA-ARS, Wenatchee Tree Fruit Research Station, Wenatchee, Wash.). In this research, the general medium potato dextrose agar (PDA) was used for culturing both fungi. Stock cultures of $P$. expansum and $B$. cinerea were stored in glycerol at $-70^{\circ} \mathrm{C}$ and the stock culture was thawed in an ice bath before use. Inoculum was obtained by diluting the stock culture with sterilized water to a spore or conidia concentration of about $3 \times 10^{5}$ cells $/ \mathrm{mL}$. 
Bioassay system. A flow-through vapor exposure system similar to that of Gardner et al. (1990), with some modification, was constructed. Under sterile conditions, $5 \mu \mathrm{L}$ of inoculum was pipetted onto the surface of apple slices and PDA-filled petri plates. There were three inoculation sites per PDA petri dish and two inoculation sites per apple slice. Exposure chambers were 10L glass desiccators, each containing four uncovered petri dishes and four apple slices. Desiccators and tubing were sterilized and contamination from nonsterilized tubing and inlet air was avoided using in-line microbial filters $(0.45-\mu \mathrm{m}$ pore size $)$. Concentrated hexanal vapors were generated by passing sterilized air through or over liquid hexanal (99.9\%, Sigma Chemical Co.) in a glass container. The hexanal vapor was mixed with hexanal-free air to obtain target hexanal concentrations by adjusting the air flow rates with glass microbore capillary tubes and a pressure regulator. Air containing hexanal was directed into the desiccator with 3-mm-i.d. flexible Teflon tubing impermeable to hexanal. The flow rate through the desiccator was 20 to $25 \mathrm{~mL} \cdot \mathrm{min}^{-1}$. Treatment concentrations of hexanal were about 4.1, 10.3, 18.6, 26.9, and 55.8 $\mu \mathrm{mol} \cdot \mathrm{L}^{-1}(100,250,450,650$, and $1350 \mathrm{ppm}$, respectively). Gas samples for hexanal and aroma volatile analysis were obtained at a sampling port fitted with a Teflon-lined septum at the outlet of the exposure chamber. Gas concentrations measured at this point were taken to represent desiccator concentrations. The atmosphere in the desiccator was humidified by passing the diluted hexanal vapor through sterilized water in a 500-mL beaker located in the desiccator. The relative humidity in the system was $>90 \%$, as determined by a electronic hydrometer (model 15-3001; Hydrodynamics).

Plant material. Apple fruit ('Jonagold' and 'Golden Delicious') were harvested from the Michigan State Univ. Clarksville Horticultural Experiment Station and stored at $0{ }^{\circ} \mathrm{C}$ until used (within 5 to $10 \mathrm{~d}$ after harvest). Fruit were warmed to ambient temperature $\left(22 \pm 1^{\circ} \mathrm{C}, 12 \mathrm{~h}\right.$ equilibration), sliced into wedges (20 to $25 \mathrm{~g}$ ), inoculated, and exposed to air with or without hexanal.

Antifungal assessments. Inoculated apple slices and petri plates were exposed to untreated air and hexanal vapor concentrations for $48 \mathrm{~h}$ in five successive experiments. For the 10.3- and 18.6$\mu \mathrm{mol} \cdot \mathrm{L}^{-1}$ treatments, an additional study was performed to determine if previously growing colonies responded to hexanal similar to germinating spores. Three inoculated petri plates for each fungus were allowed to grow in hexanal-free air for $48 \mathrm{~h}$, then transferred to the treatment chamber for a 48 -h exposure period. After treatment, the petri plates were moved again to hexanal-free air.

Hyphae growth of fungi (diameter of the colonies) was monitored daily from outside the desiccator using a scale marked on the bottom of the inverted clear glass petri dishes. Because of the difficulty of measuring the change of the colony diameter on the surface of the apple slices, only the presence (positive) and absence (negative) of a decay lesion was noted.

Hexanal analysis. A hexanal standard concentration was generated by evaporating a small amount of liquid hexanal (0.5 to 10 $\mu \mathrm{L})$ into a specially made 4.4-L glass jar fitted with an Mininert gas-tight sampling valve (Alltech Assoc., Deerfield, Ill.). After the liquid had volatilized, a $20-\mu \mathrm{L}$ gas sample was removed using a gas-tight syringe (Hamilton no. 1810) with a removable stainlesssteel needle. Pumping the syringe plunger 30 times (which apparently saturated the adsorption sites inside the needle) gave a consistent gas chromatography (GC) analysis with a CV of $2 \%$ to $5 \%$. The hexanal concentration in the treatment chambers was determined at the outlet of the desiccator. A GC (Carle GC series 400) equipped with a flame ionization detector (FID) was used to measure hexanal vapor concentrations. The column (3.3 m long, 3 mm i.d., 10\% DEGS-PS, 80/100 mesh; Supelcoport) was maintained at $140{ }^{\circ} \mathrm{C}$. Helium was used as carrier gas at flow rate of 20 $\mathrm{mL} \cdot \mathrm{min}^{-1}$.

Volatile analysis. The sampling of aroma volatiles was via a solid-phase micro-extraction (SPME) device (Supelco, Bellefonte, Pa.) fitted with a fiber coated to a thickness of $100 \mu \mathrm{m}$ with polydimethylsiloxane. The fiber was inserted through the Teflonlined septum in the outlet of the desiccator for $20 \mathrm{~s}$. Absorbed volatiles were desorbed from the fiber into the injection port of a GC (model 3400; Varian). The injector was a SPI on-column injector maintained at $200{ }^{\circ} \mathrm{C}$. The desorption time was $40 \mathrm{~s}$. Volatiles were separated using a HP-5 capillary column ( $10 \mathrm{~m}, 0.1$ $\mathrm{mm}$ i.d., $0.34 \mu \mathrm{m}$ film thickness; Hewlett Packard). Volatile detection was by a time-of-flight mass spectrometer (MS) with an electronic ionization source (FCD-650, LECO Corp, St. Joseph, Mich.). The carrier gas used was ultra purified helium (99.999\%) at a flow rate $1.2 \mathrm{~mL} \cdot \mathrm{min}^{-1}$. The temperature was isothermal for 4 min at $40{ }^{\circ} \mathrm{C}$ and then raised at the rate of $10^{\circ} \mathrm{C} / \mathrm{min}$ to $230{ }^{\circ} \mathrm{C}$ and held at $230{ }^{\circ} \mathrm{C}$ for $15 \mathrm{~min}$. The transfer line temperature was 220 ${ }^{\circ} \mathrm{C}$. Mass spectra were collected at a rate of $50 \mathrm{spectra} / \mathrm{s}$ over a mass range $\mathrm{m} / \mathrm{z} 40$ to 250 . The electron ionization energy was $70 \mathrm{eV}$.

Identification of volatile components was confirmed by comparing collected mass spectra with those of authentic compounds

Table 1. Effect of $48 \mathrm{~h}$ exposure to hexanal vapor on the hyphae growth of Penicillium expansum on potato dextrose agar in a humidified, aerobic environment at $22^{\circ} \mathrm{C}$.

\begin{tabular}{|c|c|c|c|c|c|c|c|c|}
\hline \multirow[b]{3}{*}{ Expt. } & \multirow{3}{*}{$\begin{array}{c}\text { Hexanal } \\
\left(\mu \mathrm{mol} \cdot \mathrm{L}^{-1}\right)\end{array}$} & \multicolumn{7}{|c|}{ Hyphae growth of fungi $(\mathrm{mm})^{\mathrm{z}}$} \\
\hline & & \multicolumn{7}{|c|}{ Time (h) } \\
\hline & & 24 & $48^{y}$ & 72 & 96 & 120 & 144 & 168 \\
\hline \multirow[t]{2}{*}{$\overline{1}$} & 0 & $8.0 \pm 0.05$ & $13.7 \pm 0.9$ & $19.7 \pm 1.2$ & $28.7 \pm 0.5$ & $38.6 \pm 2.53$ & $41.3 \pm 0.9$ & $50.0 \pm 1.69$ \\
\hline & 4.1 & 0 & 0 & $6.7 \pm 0.9$ & $14.6 \pm 0.5$ & $22.3 \pm 2.1$ & $29.6 \pm 0.9$ & $35.5 \pm 0.5$ \\
\hline \multirow[t]{2}{*}{2} & 0 & $6.3 \pm 0.94$ & $9.3 \pm 0.47$ & $17.2 \pm 0.7$ & $27.7 \pm 0.9$ & $34.3 \pm 0.91$ & $45.3 \pm 1.4$ & $54.6 \pm 2.1$ \\
\hline & 10.3 & 0 & 0 & 0 & $5.3 \pm 0.5$ & $10.3 \pm 0.5$ & $22.3 \pm 2.1$ & $25 \pm 2.1$ \\
\hline \multirow[t]{2}{*}{3} & 0 & $8.67 \pm 0.470$ & $16.0 \pm 4.22$ & $22.7 \pm 0.94$ & $29.3 \pm 0.9$ & $41.3 \pm 2.5$ & $44.0 \pm 2.820$ & $50.7 \pm 0.9$ \\
\hline & 18.6 & 0 & 0 & 0 & 0 & 0 & 0 & 0 \\
\hline \multirow[t]{2}{*}{4} & 0 & $5.3 \pm 0.47$ & $7.7 \pm 0.5$ & $18.6 \pm 0.9$ & $28.7 \pm 0.9$ & $31.0 \pm 1.4$ & $38.3 \pm 1.2$ & $41.0 \pm 0.8$ \\
\hline & 26.9 & 0 & 0 & 0 & 0 & 0 & 0 & 0 \\
\hline \multirow[t]{2}{*}{5} & 0 & $5.7 \pm 0.47$ & $9.4 \pm 0.94$ & $22.7 \pm 0.47$ & $33.7 \pm 0.9$ & $40.7 \pm 1.6$ & $42.7 \pm 1.6$ & $48.0 \pm 1.6$ \\
\hline & 55.8 & 0 & 0 & 0 & 0 & 0 & 0 & 0 \\
\hline
\end{tabular}

${ }^{\mathrm{z}}$ Mean \pm SD $(\mathrm{n}=3)$.

${ }^{\mathrm{y}}$ End of treatment period. 
and by comparison to spectra in the National Institute for Standard Technology (NIST) mass spectra library (Search version 1.0).

LDPE permeability to hexanal and hexylacetate. LDPE permeability to hexanal and hexylacetate was determined via a specially built permeation cell. The permeation cell was constructed of two hemispheric glass chambers, each fitted with inlet and outlet ports. The donor and receiver hemispheres were separated by the test film with an area of $7.55 \mathrm{~cm}^{2}$. Purified and humidified air with (donor side) and without (receiver side) hexanal was metered through the two chambers. On the donor side, the volatile concentration was generated in the same manner as for the vapor exposure chambers and was maintained between 2.2 and $3.5 \mu \mathrm{mol} \cdot \mathrm{L}^{-1}$. A $50-\mu \mathrm{L}$ gas sample was withdrawn using a gas-tight syringe fitted with stainless steel jacketed capillary tube as a needle. Gas analysis was the same as described previously for hexanal; however, the coating of the capillary needle accentuated the sorption of vapors, resulting in a greater amount of material being retained in the needle, thereby increasing sensitivity.

Permeability was measured at $0,5,10,15,20,25$, and $30^{\circ} \mathrm{C}$ by placing the entire apparatus in a controlled-temperature chamber. Donor- and receiver-side concentrations were determined 10 or more times at each temperature for each of two pieces of 0.00254 $\mathrm{cm}$ (1-mil)-thick LDPE film. Permeability is expressed as $\mathrm{mol} \cdot \mathrm{m} \cdot \mathrm{m}^{-2} \cdot \mathrm{s}^{-1} \cdot \mathrm{Pa}^{-1}$.

\section{Results}

Effect of hexanal on germination and growth of fungi. The 4.1$\mu \mathrm{mol} \cdot \mathrm{L}^{-1}$ treatment inhibited growth of $P$. expansum and $B$. cinerea completely during the 48-h exposure period (Tables 1 and 2). After an additional $48 \mathrm{~h}$ in hexanal-free air (hour 96), the treated colonies had grown to $50 \%$ of the control colony diameter. A concentration of $10.3 \mu \mathrm{mol} \cdot \mathrm{L}^{-1}$ prevented fungal growth during the exposure period, but also had an additional carryover effect. No growth of $B$. cinerea occurred for the next $24 \mathrm{~h}$, and $P$. expansum had no growth for $48 \mathrm{~h}$ after treatment (Tables 1 and 2). Both organisms subsequently recovered and reached about $50 \%$ of control growth by $168 \mathrm{~h}$. At concentrations of hexanal above $18.6 \mu \mathrm{mol} \cdot \mathrm{L}^{-1}$, growth of both fungi was completely arrested during the exposure period and for the subsequent $120 \mathrm{~h}$ of the experiment.

Effect of hexanal on growth of established colonies. During exposure, hexanal concentrations of 10.3 and $18.6 \mu \mathrm{mol} \cdot \mathrm{L}^{-1}$ stopped hyphae growth of established fungal colonies that had previously grown for $48 \mathrm{~h}$ in hexanal-free air (Fig. 1 a and b). Following cessation of exposure to hexanal, hyphae growth resumed for the $10.3-\mu \mathrm{mol} \cdot \mathrm{L}^{-1}$ treatment, but not following the $18.6-\mu \mathrm{mol} \cdot \mathrm{L}^{-1}$ treatment. After the $10.3-\mu \mathrm{mol} \cdot \mathrm{L}^{-1}$ treatment, regrowth of $P$. expansum was about $50 \%$ less than the control, but regrowth of $B$. cinerea was similar to that of controls. No regrowth of $P$. expansum occurred following treatment with a hexanal concentration of 18.6 $\mu \mathrm{mol} \cdot \mathrm{L}^{-1}$ (Fig. 1b). Five days after exposure to $18.6 \mu \mathrm{mol} \mathrm{L} \mathrm{L}^{-1}$ hexanal, only a slight regrowth of $B$. cinerea $(10 \%)$ was measured (Fig. 1b).

Effect of hexanal on decay of inoculated apple slices. The growth of fungi in apple slices of 'Golden Delicious' and 'Jonagold' were entirely inhibited during exposure to 10.3 and $18.6 \mu \mathrm{mol} \cdot \mathrm{L}^{-1}$ hexanal vapor (Table 3 ). Following exposure, no lesion expansion was observed. No effect of hexanal vapor on the color of either the cortex or the skin was observed for any of the treatments.

Effect of hexanal on aroma. Aroma volatiles exiting the control (hexanal-free) chamber were not detectable for either 'Jonagold' or 'Golden Delicious' slices (data not shown). However, there was significant aroma production by apple slices after only $0.5 \mathrm{~h}$ exposure to $10.3 \mu \mathrm{mol} \cdot \mathrm{L}^{-1}$ hexanal for both cultivars (Fig. 2 a and b). Aroma data are presented as the ratio of aroma to hexanal concentration in the exit line as an estimate the relative rate of metabolic conversion of hexanal to aroma volatiles by the apple slices. For 'Jonagold', hexanal interconversion to hexanol was immediately detected; however, hexylacetate production began to increase only after $5 \mathrm{~h}$ (Fig. 2a). After $7.5 \mathrm{~h}$, the production of butylhexanoate and hexylhexanoate was detectable; by the end of the exposure period $(50 \mathrm{~h})$, their ratio relative to hexanal in the chamber exit line increased to 0.06 and 0.08 , respectively. Additionally, after $24 \mathrm{~h}$, traces of hexylbutanoate, 2-methylpropylhexanoate, propylhexanoate, and butylbutanoate were also identified by GC-MS (data not shown) and had the same temporal trends as hexylacetate. At $30 \mathrm{~h}$, the chamber hexylacetate concentration reached the highest level, about 1.5 times that of hexanal. This maximum was followed by a decline in the hexylacetate/ hexanal ratio to about 0.5 by hour 50 . 'Golden Delicious' slices, like those of 'Jonagold', continuously converted hexanal to hexanol, hexylacetate and hexylhexanoate, but at somewhat different rates (Fig. 2b). The ratio of hexanol to hexanal was 1.5 after $18 \mathrm{~h}$; however, the highest ratio for hexylacetate was just 0.4 and occurred after $26 \mathrm{~h}$. The ratio of butylhexanoate and hexylhexanoate to hexanal only reached 0.1 at the end of the exposure period,

Table 2. Effect of $48 \mathrm{~h}$ exposure to hexanal vapor on the hyphae growth of Botrytis cinerea on potato dextrose agar in a humidified, aerobic environment at $22{ }^{\circ} \mathrm{C}$.

\begin{tabular}{|c|c|c|c|c|c|c|c|c|}
\hline \multirow[b]{3}{*}{ Expt. } & \multirow{3}{*}{$\begin{array}{c}\text { Hexanal } \\
\left(\mu \mathrm{mol} \cdot \mathrm{L}^{-1}\right)\end{array}$} & \multicolumn{7}{|c|}{ Hyphae growth of fungi $(\mathrm{mm})^{\mathrm{z}}$} \\
\hline & & \multicolumn{7}{|c|}{ Time (h) } \\
\hline & & 24 & $48^{y}$ & 72 & 96 & 120 & 144 & 168 \\
\hline \multirow[t]{2}{*}{1} & 0 & $4.7 \pm 0.05$ & $21.7 \pm 2.3$ & $31.3 \pm 0.9$ & $44.3 \pm 0.5$ & $50.7 \pm 1.25$ & $54.6 \pm 1.3$ & $59.4 \pm 0.9$ \\
\hline & 4.1 & 0 & 0 & 0 & $11.0 \pm 0.8$ & $23.3 \pm 2.35$ & $37.6 \pm 0.5$ & $42.0 \pm 1.6$ \\
\hline \multirow[t]{2}{*}{2} & 0 & $6.3 \pm 0.94$ & $9.3 \pm 0.47$ & $17.6 \pm 0.7$ & $27.7 \pm 0.9$ & $34.3 \pm 0.9$ & $45.3 \pm 1.4$ & $54.6 \pm 0.9$ \\
\hline & 10.3 & 0 & 0 & 0 & 0 & $4.3 \pm 1.2$ & $12.7 \pm 0.9$ & $22.7 \pm 0.9$ \\
\hline \multirow[t]{2}{*}{3} & 0 & $7.33 \pm 0.5$ & $19.3 \pm 2.35$ & $30.7 \pm 0.94$ & 40.3 & $46.7 \pm 1.24$ & $50.3 \pm 1.24$ & $56.7 \pm 0.5$ \\
\hline & 18.6 & 0 & 0 & 0 & 0 & 0 & 0 & 0 \\
\hline \multirow[t]{2}{*}{4} & 0 & $5.3 \pm 0.4730$ & $10.3 \pm 0.5$ & $14.0 \pm 0.9$ & $23.3 \pm 1.3$ & $38.7 \pm 0.9$ & $46.7 \pm 2.4$ & $58.0 \pm 0.5$ \\
\hline & 26.9 & 0 & 0 & 0 & 0 & 0 & 0 & 0 \\
\hline \multirow[t]{2}{*}{5} & 0 & $5.3 \pm 0.47$ & $19.4 \pm 0.94$ & $24.2 \pm 0.47$ & $34.3 \pm 0.9$ & $40.7 \pm 0.9$ & $47.4 \pm 2.05$ & $56.7 \pm 2.05$ \\
\hline & 55.8 & 0 & 0 & 0 & 0 & 0 & 0 & 0 \\
\hline
\end{tabular}

\footnotetext{
${ }^{\mathrm{z}}$ Mean \pm SD $(\mathrm{n}=3)$.
}

yEnd of treatment period. 

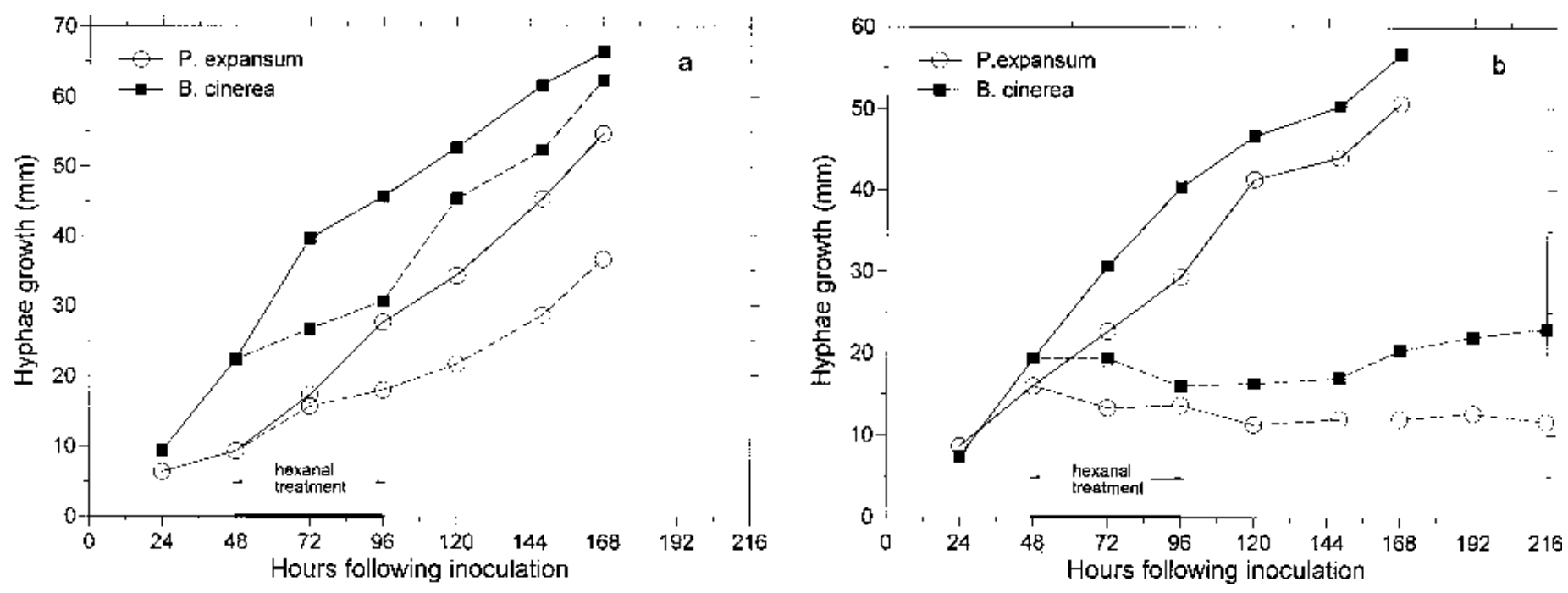

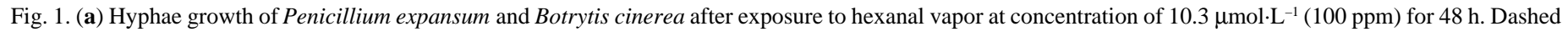

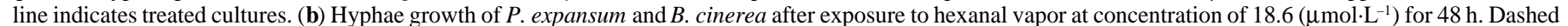
line indicates treated cultures.

which was slightly higher than for 'Jonagold'.

Hexanal and aroma emanations aftertreatmentcessation. Hexanal could not be detected emanating from treated slices $16 \mathrm{~h}$ after treatment with hexanal at a concentration of $10.3 \mu \mathrm{mol} \cdot \mathrm{L}^{-1}$ (Fig. 3). The lower limit of detection of our system was about $4.13 \times 10-5$ $\mu \mathrm{mol} \cdot \mathrm{L}^{-1}(1 \mathrm{ppb})$, which is below the odor threshold for humans (Devos et al., 1990). A rapid decrease in hexanol, hexylacetate, and hexylhexanoate occurred following treatment, with hexanol declining more rapidly than the other four primary metabolic products of hexanal and hexylacetate declining least rapidly.

LDPE permeability to hexanal and hexylacetate. The permeability of hexanal and hexylacetate increased exponentially with temperature increase (Fig. 4). The natural log of the permeability changed linearly with reciprocal of temperature $(\mathrm{K})$ according to the Arrhenius equation:

$$
\ln (\mathrm{Pi})=-\mathrm{Ea} / \mathrm{RT}+\ln (\mathrm{A})
$$

where Pi is hexanal or hexylacetate permeability $\left(\mathrm{mol} \cdot \mathrm{m} \cdot \mathrm{m}^{-2} \cdot \mathrm{s}^{-1} \cdot \mathrm{Pa}^{-1}\right)$; Ea is the energy of activation $\left(\mathrm{kJ} \cdot \mathrm{mol}^{-1}\right)$; and $\mathrm{R}$ is the gas constant $\left(0.0083144 \mathrm{~kJ} \cdot \mathrm{mol}^{-1} \cdot \mathrm{K}^{-1}\right)$. The slope of the fitted line is $-\mathrm{Ea} / \mathrm{R}(\mathrm{Fig}$. 4 , insert). The Ea for permeation of the gases was calculated from the fitted line and was $44.6 \mathrm{~kJ} \cdot \mathrm{mol}^{-1}$ for hexanal and $23.6 \mathrm{~kJ} \cdot \mathrm{mol}^{-1}$ for hexylacetate with respective coefficient of determination $\left(r^{2}\right)$ values of 0.99 and 0.94 . The equations of the fitted lines were rearranged to facilitate expression of $\mathrm{P}_{\text {hexanal }}$ and $\mathrm{P}_{\text {hexylacetate }}$ for the LDPE film at any $\mathrm{T}(\mathrm{K})$ as follows:

$$
\begin{aligned}
& \mathrm{P}_{\text {hexanal }}=0.53495 \times \exp (-5364.1 / \mathrm{T}) \\
& \mathrm{P}_{\text {hexylacetate }}=0.00032 \times \exp (-2832.6 / \mathrm{T})
\end{aligned}
$$

Hexanal permeability was lower than that of hexylacetate. The permeability of both compounds increased exponentially with temperature, with hexanal permeability increased 6-fold while hexylacetate increased only 2.5 fold between 0 and $30^{\circ} \mathrm{C}$.

\section{Discussion}

Lipoxygenase-related volatiles may play a role in plant response to wounding and other related stresses (Hildebrand et al., 1988).
A burst of lipoxygenase activity accompanying wounding of the cell leads to the production of fatty acid hydroperoxides, or their decomposition to compounds like $\mathrm{C}_{6}$ - and $\mathrm{C}_{9}$-aldehydes (Galliard, 1978). Drawert et al. (1973) reported that the identified $\mathrm{C}_{6}$ aldehydes, hexanal, (Z)-3-hexenal, and (E)-2-hexenal produced enzymatically when cellular structures are disrupted in green vegetables. These lipoxygenase reaction products can act as toxic agents to invading pathogens (Hildebrand et al., 1988). The findings of significant antifungal effects of hexanal in our experiment using the quantitative vapor system demonstrated that hexanal was effective in reducing fungal activity during the exposure period and, at higher concentrations, had a residual effect, preventing fungal regrowth probably due to a fungicidal action.

The inhibitory effect of hexanal vapors on the growth of $P$. expansum and $B$. cinerea is well supported by the literature (Wilson et al., 1991). A number of natural volatile compounds have been found to have antipathogenic effects. These compounds fall in various chemical categories but are primarily aldehydes and ketones. Natural antifungal volatiles examine for commercial applicability include acetaldehyde (Aharoni and Stadelbacher, 1973; Avissar et al., 1989), 2-nonanone (Vaughn et al., 1993), ethyl benzoate (Wilson et al., 1987), acetic acid (Sholberg and Gaunce, 1995), and $\mathrm{C}_{6}$-aldehydes such as hexanal and trans-2hexenal (Hamilton-Kemp et al., 1992).

A primary concern in the application of antifungal volatile compounds having aromas is the alteration of fruit flavor. Acetaldehyde, for instance, has been reported to cause off-flavor (Paillard, 1990) as well as improved flavor (Paz et al., 1982). The strong

Table. 3. Effect of hexanal vapor exposure for $48 \mathrm{~h}$ on lesion growth of Penicillium expansum

\begin{tabular}{|c|c|c|c|c|c|c|c|}
\hline \multirow[b]{3}{*}{ Expt. } & \multirow{3}{*}{$\begin{array}{c}\text { Hexanal } \\
\left(\mu \mathrm{mol} \cdot \mathrm{L}^{-1}\right)\end{array}$} & \multicolumn{3}{|c|}{ Penicillium expansum } & \multicolumn{3}{|c|}{ Botrytis cinerea } \\
\hline & & \multicolumn{6}{|c|}{$\overline{T i m e}(\mathrm{~h})$} \\
\hline & & 24 & 48 & 72 & 24 & 48 & 72 \\
\hline \multirow[t]{2}{*}{1} & 0 & - & + & + & - & - & + \\
\hline & 10.3 & - & - & - & - & - & - \\
\hline \multirow[t]{2}{*}{2} & 0 & - & + & + & - & - & + \\
\hline & 18.6 & - & - & - & - & - & - \\
\hline
\end{tabular}
and Botrytis cinerea on slices of 'Jonagold' apple fruit. Symbols indicate presence $(+)$ or absence (-) of decay lesions. 

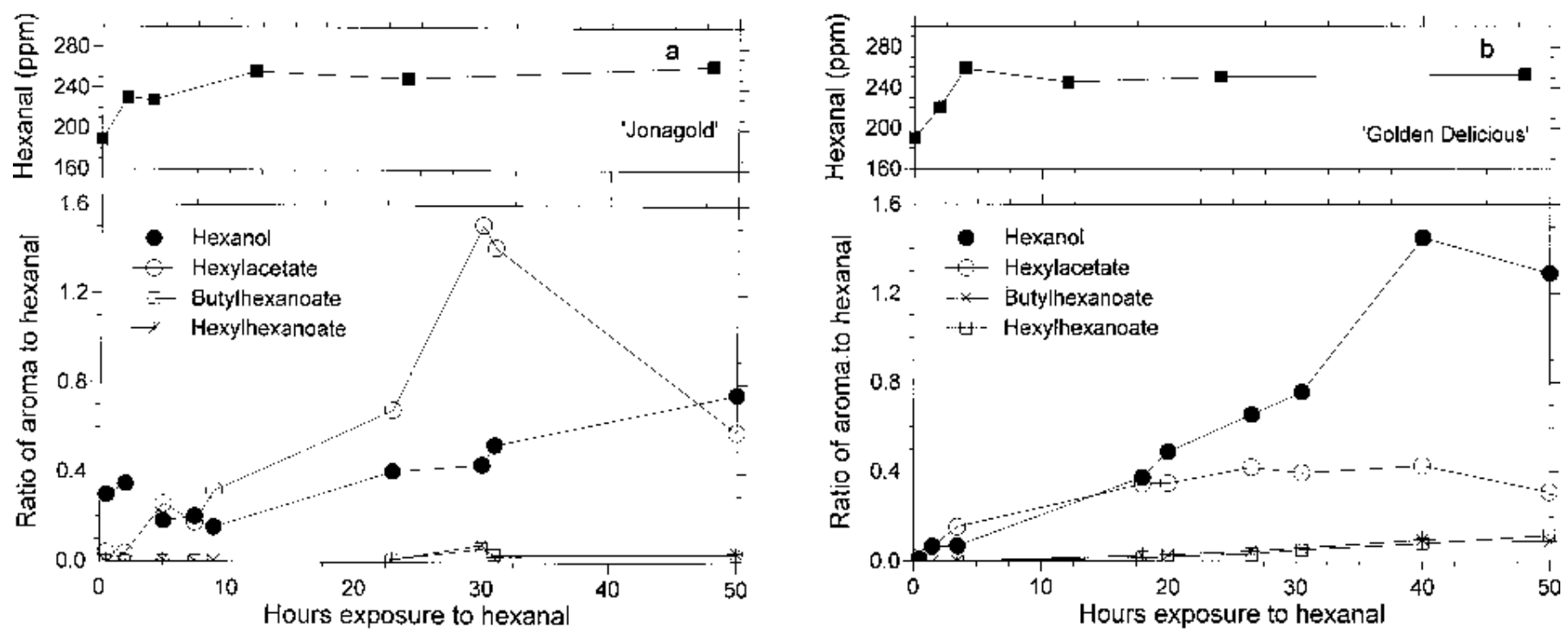

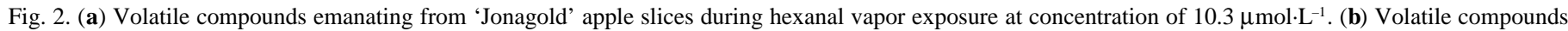
emanating from 'Golden Delicious' apple slices during hexanal vapor exposure at concentration of $10.3 \mu \mathrm{mol} \cdot \mathrm{L}^{-1}$.

fruity-floral aroma of 2-nonanone may be incompatible with some fruit types, such as apple. Additionally, for apple, concentrations of 2-nonanone below that needed to inhibit decay organisms induced browning of the apple skin (Leepipattanawit, unpublished data). Hexanal treatment, however, may not pose similar problems. Aldehydes such as hexanal and their oxidation products such as hexanol and hexanoic acid act as precursors for a wide range of 'fruity' aroma volatiles important to fruit flavor (Bartley et al., 1985; Drawert et al., 1973). Thus, hexanal vapor is consumed as it is converted to compounds that enhance aroma in apple (De Pooter et al., 1983; Song, 1994). The metabolism of hexanal would explain our inability to detect hexanal emanations from treated fruit by either instrument or smell $16 \mathrm{~h}$ after cessation of hexanal treatment. The ability of apple tissues to metabolize hexanal is also consistent with the rapid decline in hexanol and the other aroma volatiles we detected following cessation of hexanal treatment. Similarly, Song (1994) found hexanal enhancement of aromas to last only a few days following exposure.

The enzyme system responsible for this interconversion of aldehydes to alcohols to esters is the sequential reactions of alcohol dehydrogenase (ADH, E.C 1.1.1.1) and alcohol acetyltranferase (AAT, E.C 2.3.1.84). These enzymes were apparently highly active in apple slices. It is interesting to note that the small mass of apple tissue (about $80 \mathrm{~g}$ ) being used in our experiment converted most of the supplied hexanal to hexanol and, subsequently, hexylacetate and related compounds. The dynamics of the conversion of hexanal to hexanol and hexanol to hexylacetate in 'Jonagold' and 'Golden Delicious' slices is consistent with earlier findings that the precursor availability, rather than enzyme activities, is perhaps the most important factor for regulating volatile production in apple fruit (Bartley et. al, 1985; Song and Bangerth, 1994). The two cultivars in this study differed somewhat in their response to hexanal application. While 'Jonagold' fruit exhibited a significant capacity to synthesize hexanol at the initiation of the experiment, 'Golden Delicious' did not. In fact, the 'Golden Delicious' fruit exhibited a continued increase in their capacity to convert hexanal to hexanol, which may be indicative of an increase in the capacity of ADH over time. 'Jonagold' fruit, on the other hand, appeared to undergo an increase in the competence of AAT activity with time.
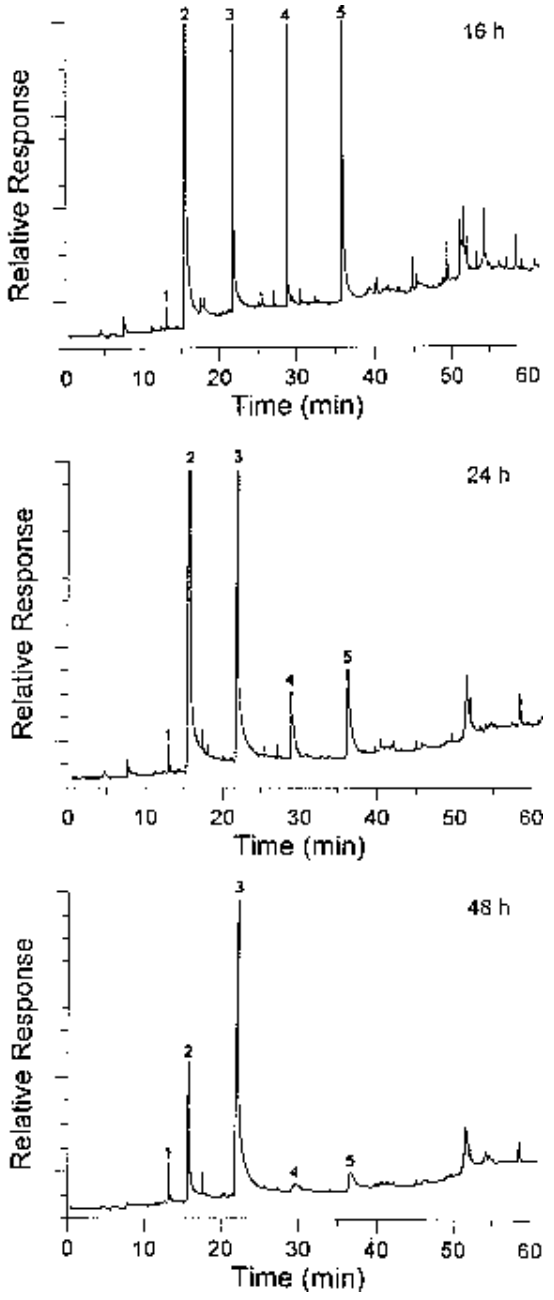

Fig. 3. Decline in volatile compounds emanating from 'Golden Delicious' apple slices with time after exposure to a hexanal vapor concentration of $10.3 \mu \mathrm{mol} \cdot \mathrm{L}^{-1}$. (1, butylacetate; 2 , hexanol; 3 , hexylacetate; 4 , butylhexanoate; 5 , hexylhexanoate). 


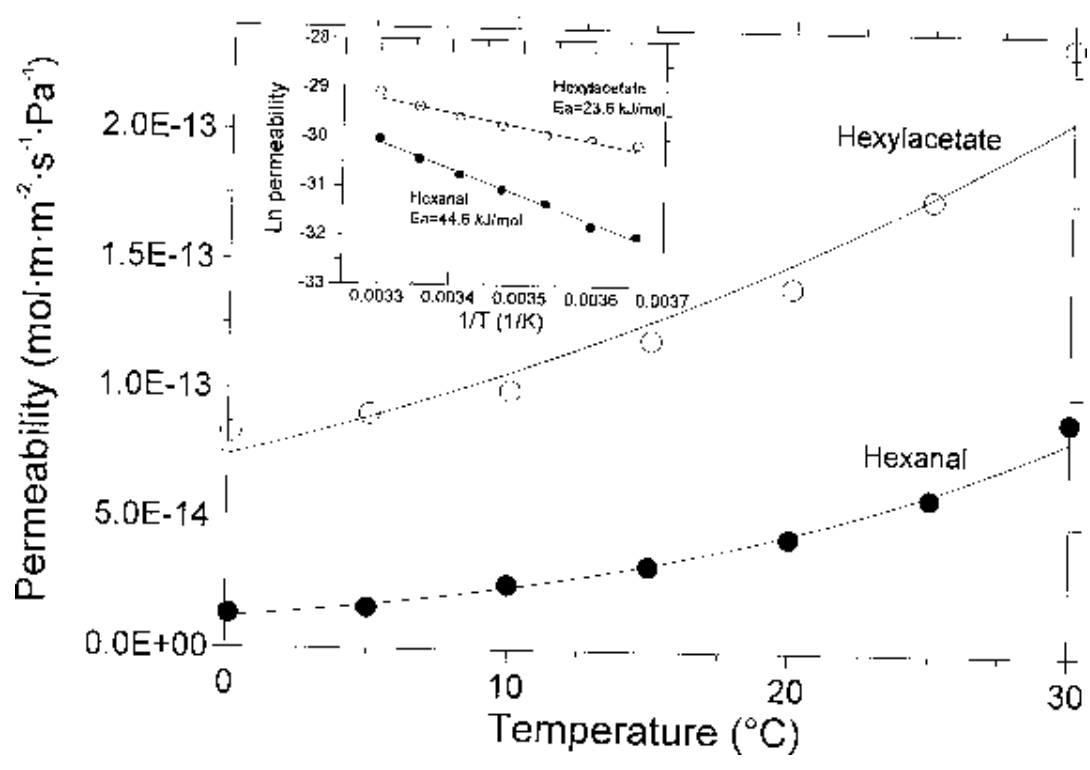

Bartley, I.M., P.G. Stoker, A.D.E. Martin, S.G.S. Hatfield, and M. Knee. 1985. Synthesis of aroma compounds by apples supplied with alcohols and methyl esters of fatty acids. J. Sci. Food Agr. 36:567574.

Beaudry, R.M., A.C. Cameron., A. Shirazi, and D.L. Dostal-Lange. 1992. Modified-atmosphere packaging of blueberry fruit: Effect of temperature on packaging $\mathrm{O}_{2}$ and $\mathrm{CO}_{2}$. J. Amer. Soc. Hort. Sci. 117:436-441.

Cameron, A.C., P.C. Talasila, and D.W. Joles. 1995. Predicting film permeability needs for modified atmosphere packaging of lightly processed fruits and vegetables. HortScience 30:25-34.

Debeaufort, F. and A. Voilley. 1994. Aroma compound and water vapor permeability of edible films and polymeric packaging. J. Agr. Food. Chem. 42:2871-2875.

Delassus, P.T., J.C. Tou, M.A. Babinec, D.C Rulf, B.K. Karp, and B.A. Howell. 1988. Transport of apple aromas in polymer films, p. 1127. In: J.H. Hotchkiss (ed.). Food and packaging interactions. ACS Symp. Ser. 365

De Pooter, H.L., J.P. Montens, G.A. Willaert, P.J. Dirinck, and N.M. Schamp. 1983. Treatment of Golden Delicious apples with aldehydes and carboxylic acids: Effect on the headspace composition. J. Agr. Food Chem. 31:813-818

Devos, M., F. Patte, J. Rouault, P. Laffort, and L.J. Van Gemert. 1990. Standardized human olfactory thresholds. Oxford Univ. Press, New York.

Drawert, F., R. Tressl, W. Heimann, R. Emberger, and M. Speck 1973. Über die biogenese von aromastoffen bei pflanzen und früchten.

Fig. 4. Effect of temperature on LDPE permeability to hexanal and hexylacetate $\left(\mathrm{P}_{\text {hexanal }}\right.$ and $\left.\mathrm{P}_{\text {hexylacetate }}\right)$. Insert: Arrhenius plot of hexanal and hexylacetate permeability for typical film sample.

Modified-atmosphere packaging storage has some potential as an atmospheric control system to prolong the storage life of perishable products (Beaudry et al., 1992; Cameron et al., 1995). If the concept of atmospheric control is expanded to include introduced volatiles, the application of volatiles in a packaging system to prevent decay may be appropriate for apple slices (Lakakul, 1994). The permeability data here show that LDPE is a relatively poor barrier to hexanal and hexylacetate, and the data are consistent with reported values (Delassus et al., 1988). This suggests hexanal introduced into the package headspace would escape rapidly. The higher Ea for hexanal compared to hexylacetate indicates hexanal retention would be relatively better at lower temperatures. The permeability of hexanal and each of its metabolic products can be used to develop models to describe their flux similar to models developed for $\mathrm{O}_{2}$ and $\mathrm{CO}_{2}$ (Cameron et al., 1994). If need be, a gaseous release mechanism such as that described by Vaughn et al. (1993) might be used to release a predictable level of vapor into the package headspace to compensate for that lost from the package. It is also conceivable that more polar films might be appropriate (Debeaufort and Voilley, 1994).

Our data suggest hexanal vapor has a number of attributes that may be important to consumers demanding more natural control measures for fruit diseases and fewer toxic residues. In addition, hexanal-derived aroma enhancement may also prove desirable. Significantly, fruit of a number of horticulturally important plant species utilize $\mathrm{C}_{6}$-aldehydes as precursors to aromas. This suggests hexanal and similar aldehydes can be used rather widely as antifungal agents. Fruit having some potential for aldehyde application include pears, strawberries, bananas, pineapple, and melons. Aldehyde use in packaging of lightly processed products of these commodities also seems to be a possible future option.

\section{Literature Cited}

Aharoni, Y. and G.J. Stadelbacher. 1973. The toxicity of acetaldehyde vapor to postharvest pathogens of fruits and vegetables. Phytopathology 63:544-545.

Avissar, I., R. Marinansky, and E. Pesis. 1989. Postharvest decay control of grape by acetaldehyde vapors. Acta Hort. 258: 655-660.

$\mathrm{XV}$. Enzymatische-oxidative bildung von $\mathrm{C}_{6}$-aldehyden und alkoholen und deren vorstufen bei äpfeln und Trauben. Chem. Mikrobiol. Technol. Lebenm. 2:10-22.

Galliard, T. 1978. Lipolytik and lipoxygenase enzymes in plants and their action in wounded tissues, p. 155-201. In: G. Kahl (ed.). Biochemistry of wounded plant tissues. Walter de Gruyter, Berlin.

Gardner, H.W., D.L. Dornbos, and A.E. Desjardins. 1990. Hexanal, trans-2-hexenal, and trans-2-nonenal inhibits soybean, Glycine max, seed germination. J. Agr. Food. Chem. 38:1316-1320.

Hamilton-Kemp, T.R., C.T. MaCracken, J.H. Loughrin, R.A. Anderson, and D.F. Hildebrand. 1992. Effect of some natural volatile compounds on the pathogenic fungi Alternaria alternata and Botrytis cinerea. J. Chem. Ecol. 18:1083-1091

Hildebrand, D.F., T.R. Hamilton-Kemp., C.S. Legg, and G. Bookjans. 1988. Plant lipoxygenase: occurrence, properties and possible functions. Curr. Top. Plant. Biochem. Physiol. 7:210-209.

Jeffries, P. and M.J. Jeger. 1990. Biological control of postharvest diseases of fruits. Postharvest News Info. 5:365-368.

Kelman, A. 1989. Introduction: The importance of research on the control of postharvest disease of perishable food crops. Phytopathology 1374.

Lakakul, R. 1994. Modified-atmosphere packaging of apple slices: Modeling respiration and package oxygen partial pressure as function of temperature and film characteristics. MS thesis, School of Packaging, Michigan State Univ.

Paillard, N.M.M. 1986. Evolution of the capacity of aldehyde production by crushed apple tissues, during an extended storage of fruits, p. 368-378. In: G. Charalambous (eds.). The shelf life of foods and beverages. Proc. 4th Intl. Flavor Conf. Elsevier Science Publishers B.V., Amsterdam

Paillard, N.M.M. 1990. The flavor of apples, pears and quinces, p. 1-42. In: I.D. Morton and A.J. MaCleod (eds.). Food flavors. Part C: The flavor of fruits. Elsevier Science Publishers B.V., Amsterdam

Paz, O., H.W. Janes, B.A. Prevost, and C. Frenkel. 1982. Enhancement of fruit sensory quality by post-harvest applications of acetaldehyde and ethanol: Blueberries, tomatoes, pears. J. Food. Sci. 47:270-273.

Sholberg, P.L. and A.P. Gaunce. 1995. Fumigation of fruit with acetic acid to prevent postharvest decay. HortScience 30:1271-1275.

Song, J. 1994. Einfluss verschiedener Erntzeitpunkte auf die Fruchtreif unter besonderer Berüksichtigung der Aromabilding bei Äpfeln, Tomaten und Erdbeeren. Verlag Ulrich E. Grauer. Stuttgart, Germany

Song, J. and F. Bangerth. 1994. The production and changes of volatile compounds from apple fruits of different maturities. Acta Hort. 368:150-159.

Vaughn, S.F., G.F. Spence, and B.S. Shasha. 1993. Volatile compounds from raspberry and strawberry fruit inhibit postharvest decay fungi. J. Food Sci. 58: 793-796.

Vick, B.A. and D.C. Zimmerman. 1987. Oxidative systems for modification of fatty acids: The lipoxygenase pathway, p. 53-90. In: P.K. Stumpf (ed.). The biochemistry of plants. vol. 9. Academic Press.

Wilson, C.L., J.D. Franklin, and B.E. Otto. 1987. Fruit volatiles inhibitory to Monilinia fructicola and Botrytis cinerea. Plant Dis. 71:316-319.

Wilson, C.L., M.E. Wisniewski, C.L. Biles, R. McLaughlin, E. Chalutz, and S. Droby. 1991. Biological control of postharvest diseases of fruits and vegetables: Alternatives to synthetic fungicides. Crop Protection. 10:172-177.

Wisniewski, M.E. and C.L. Wilson 1992. Biological control of postharvest diseases of fruits and vegetables: Recent advances. HortScience 27:94-98. 